\title{
Study of the bone pathology in early mucolipidosis II (I-cell disease)
}

\author{
U.E.Pazzaglia ${ }^{1}$, G. Beluffi ${ }^{2}$, E. Bianchi ${ }^{3}$, A.Castello ${ }^{4}$, A.Coci $^{4}$, and A.Marchi ${ }^{3}$ \\ ${ }^{1}$ Clinica Ortopedica e Traumatologica dell'Universitá di Pavia, and ${ }^{2}$ Servizio di Radiodiagnostica, I.R.C.C.S. Policlinico San Matteo, \\ Via Taramelli 3, I-27100 Pavia, Italy \\ ${ }^{3}$ Clinica Pediatrica dell'Universitá di Pavia, Pavia, Italy \\ ${ }^{4}$ Dipartimento di Patologia Umana ed Ereditaria, Sezione di Anatomia Patologica, Pavia, Italy
}

\begin{abstract}
Histological examination of the bones obtained on autopsy of a 5-month-old child with mucolipidosis II (I-cell disease) revealed inhibition of the growth plate calcification with defective vascular invasion and signs of hyperparathyroidism. These findings are the chondro-osseous basis of the early radiological ricket-like appearance of bones in the neonatal period or soon thereafter. Whether the early skeletal abnormalities of mucolipidosis II result from a primary enzymatic defect of cartilage and bone cells or from factors controlling bone metabolism deserves further study.
\end{abstract}

Key words: Mucolipidosis II - I-cell disease - Dysostosis multiplex - Rickets - Hyperparathyroidism

\section{Introduction}

Dysostosis multiplex is a constant finding in mucolipidosis II. The progression of the skeletal abnormalities with age $[2,5,7$, $8]$ may result from the same storage process in bone cells as in viscera or from the effect of factors controlling bone turnover. No evidence supporting either of these hypotheses has been presented and few histological studies of bone are available $[1,3,6,9,10]$. We describe a child with I-cell disease, who died at 5 months of age and report a detailed study of the bone alterations.

\section{Case report}

The patient born on 17 January 1986, was the second son of first cousins whose first son was normal. The family history was negative. The child was born at 38 weeks of gestation. The birth weight was $2800 \mathrm{~g}$ and weight gain in the first 2 months was reported to be normal. He was admitted for the first time at the age of 2 months because of a left hydrocele. The following physical findings were observed: microcephalus, hypertelorism, low-set ears, high-arched palate, hypertrophic gums, generalized muscle hypotonia, breathing difficulty. A skeletal survey showed generalized osteoporosis with coarse, lacy trabeculae and a spongy appearance of diaphyseal cortical bone. Periosteal thickening, cupping and irregularity of the metaphyses were evident in the long bones. High values of serum alkaline phosphatase $(2950,3130,2810$, $2098 \mathrm{U} / 1)$ were repeatedly observed. Serum calcium and phos-

Offprint requests to: U. E. Pazzaglia phate were low (Ca from 6.6 to $8.46 \mathrm{mg} / \mathrm{dl}$ and $\mathrm{PO}_{4}$ from 2.21 to $3.82 \mathrm{mg} / \mathrm{dl}$ ), urinary calcium was low, while phosphate was high. Serum parathyroid hormone level was elevated $(1.7 \mu \mathrm{g} /$ $\mathrm{ml})$. The only other abnormalities were mild leukocytosis and hypochromic anaemia. A diagnosis of skeletal dysplasia with hypophosphataemic rickets was made and treatment with vita$\min \mathrm{D}(50,000 \mathrm{IU} /$ day $)$ and sodium phosphate $(1 \mathrm{~g} /$ day) was started. Following therapy no improvement was observed.

At the age of 5 months the child was admitted to the Paediatric Department of the University of Pavia. Weight was $3830 \mathrm{~g}(<10$ th percentile); height $56.6 \mathrm{~cm}(<10$ th percentile); head circumference $41 \mathrm{~cm}$ ( $<10$ th percentile). The baby's general condition was poor with pale skin, hypotrophic muscles and scanty subcutaneous tissue. The anterior fontanelle was $0.5 \mathrm{~cm} \times 1 \mathrm{~cm}$. The child had no teeth and the gums were markedly hypertrophic; the nostrils were anteverted. The chest was funnel shaped, the sternum bowed and the costosternal junctions were hypertrophic. Heart sounds were normal, the liver was palpable $3 \mathrm{~cm}$ below the costal margin. Small superficial lymph nodes were present. Routine laboratory tests were normal except for leukocytosis and hypochromic anaemia. Alkaline phosphatase was $1747 \mathrm{mU} / \mathrm{ml}$ (normal range $120-700 \mathrm{mU} / \mathrm{ml}$ ) and serum phosphate $6.63 \mathrm{mg} / \mathrm{dl}$ (normal range $4-7 \mathrm{mg} / \mathrm{dl}$ ). Amino acids and glucose were absent in the urine. The child died before parathyroid hormone levels could be determined.

Skin fibroblasts were cultured and lysosomal enzymes were assayed in plasma, leukocytes and fibroblasts (Table 1). Cultured fibroblasts showed characteristic cytoplasmic inclusions.

Table 1. Levels of acid hydrolases in plasma, leucocytes and fibroblasts

\begin{tabular}{lll}
\hline Acid hydrolases & Plasma & Fibroblasts \\
\hline Arylsulphatase A & $84.45 \Delta / \mathrm{ml} / \mathrm{h}(1.44)$ & $14.85-23.92 \Delta / \mathrm{mg} / \mathrm{h}$ \\
& & $(150-500)$ \\
Total hexosaminidases & $14727 \Delta / \mathrm{ml} / \mathrm{h}(735.43)$ & $393.07-854.57 \Delta / \mathrm{mg} / \mathrm{h}$ \\
& $(3000-10000)$ \\
3-galactosidase & $11.34-11.84 \Delta / \mathrm{mg} / \mathrm{h}$ \\
& $(300-800)$ \\
$\alpha$-mannosidase & $13.26-14.09 \Delta / \mathrm{mg} / \mathrm{h}$ \\
& $(54.8-120.7)$ \\
\hline
\end{tabular}

()$=$ control values

Arylsulphatases A activity in leucocytes was $95 \%$ of controls (not significant) 

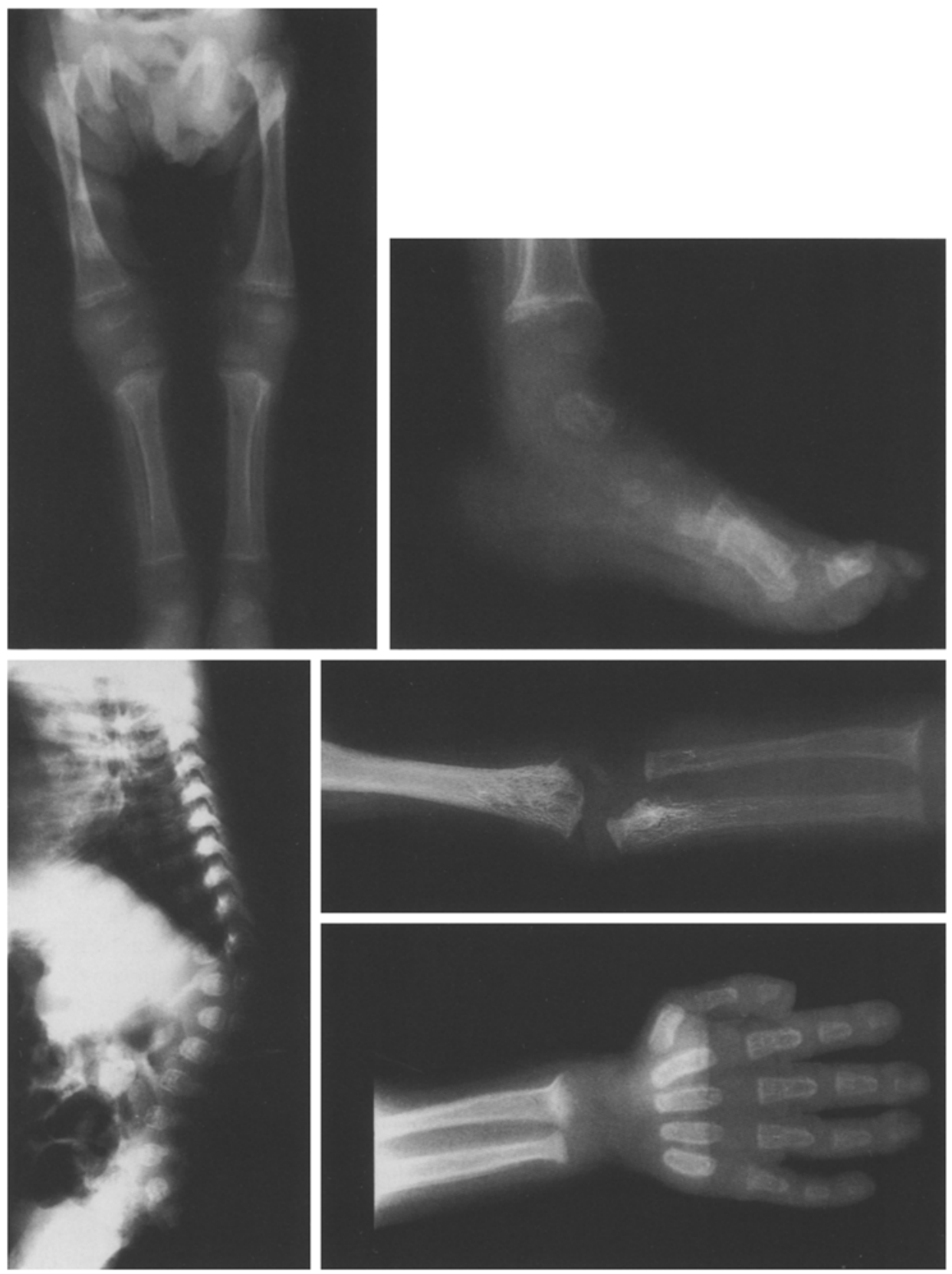

Fig. 1. Radiographic appearance. Lower limbs: frayed metaphyses with a sclerotic horizontal line; the proximal metaphyses of the tibiae have a medial to lateral tapering, while the proximal left femur is bent medially; cloaking of diaphyses is evident in the tibiae. Small flecks of calcium are present below the irregular nucleus of the astragalus; cupped, rachitic-like appearance of the distal tibia and fibula. Spine and upper limbs: osteopenia, abnormal trabecular pattern and cloaking of tubular bones; a cupped, ricket-like aspect of metaphysis is particularly evident in the distal radius; bulletshaped phalanges in the hands

\section{Radiographic findings}

Bone survey showed generalized osteopenia with the exception of the bones of the base of the skull which were thickened and sclerotic. Maxilla and mandible were undermineralized and the teeth seemed to float within the poorly textured bone. The long bones were osteoporotic with enlarged medullary canals, coarsely structured with thin trabeculae and a cloaklike appearance of the entire shaft of the tubular bones of the lower limbs. The metaphyses of the long bones were frayed and those of the distal ulnae, radii, tibiae and fibulae also cupped with submetaphyseal bone resorption which in the distal femura and proximal tibiae was limited by a sclerotic horizontal line (Fig. 1). The scapulae were poorly calcified and misshapen with an irregular texture and shallow glenoid cavities; the clavicles were deformed and the ribs short and broad with cup-like distal ends. Narrowing of the interpeduncular dis- tance in the lower thoracic spine was present. In the lateral view, ovoid vertebral bodies with some anterior beaking of the first and second lumbar vertebrae were associated with a dorso-lumbar kyphosis (Fig. 1). Other findings were proximal pointing of metacarpal bones, brachyphalangy with bulletshaped phalanges (Fig.1), stippling of the tarsus, flared iliac wings, and a horizontal acetabular roof with supra-acetabular constriction.

The bone changes had progressed compared to films taken 2 months earlier where bone rarefaction was already present but signs of sub-periosteal resorption less evident.

\section{Pathology}

Autopsy was performed $24 \mathrm{~h}$ after death. The following bones were studied: right tibia, 4th, 5th and 6th right ribs, 4th, 5th 

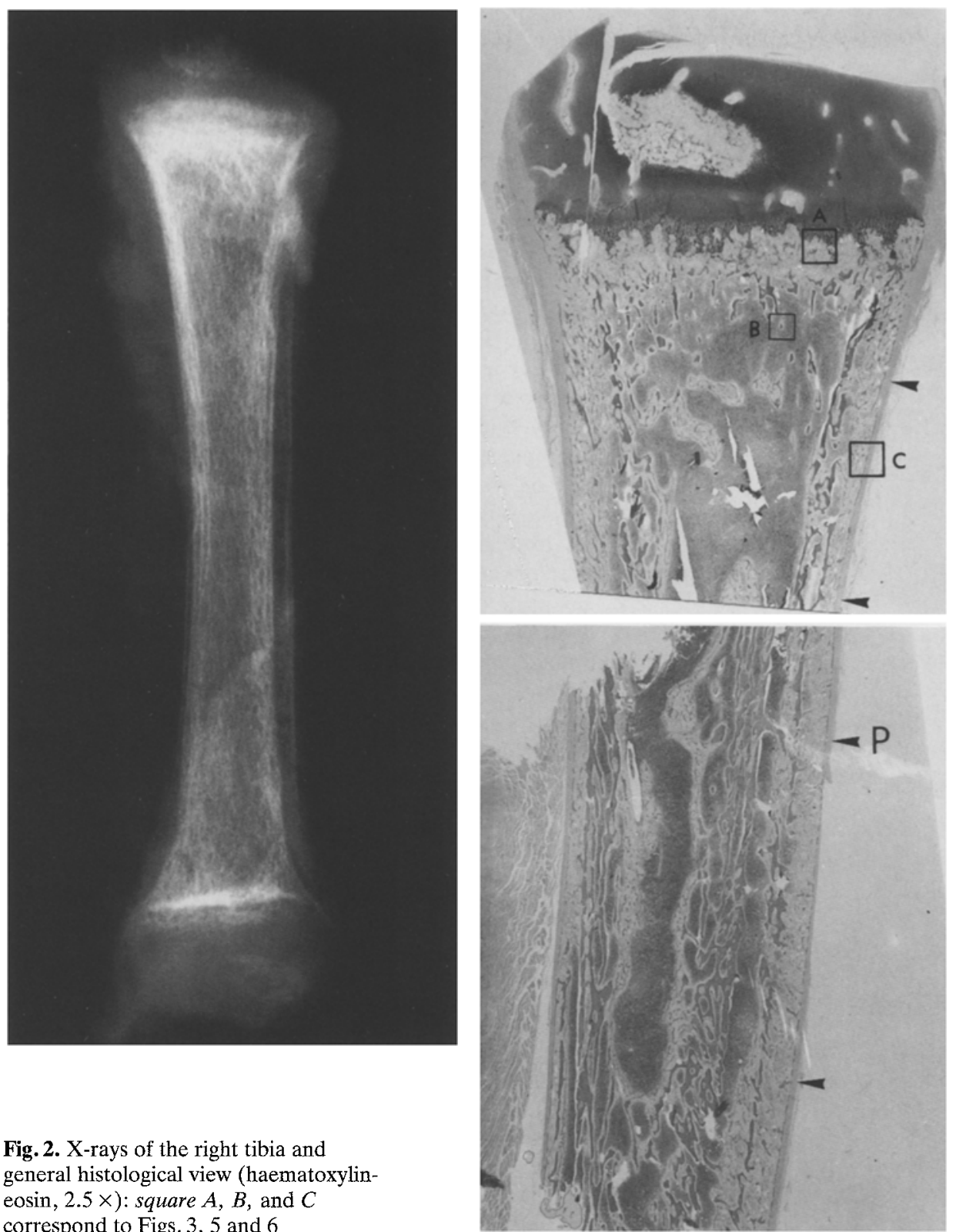

Fig. 2. X-rays of the right tibia and general histological view (haematoxylineosin, $2.5 \times)$ : square $A, B$, and $C$ correspond to Figs. 3,5 and 6

and 6 th dorsal vertebrae and sternum. All bones examined were softer than normal.

The growth plate had abnormally high columnar and hypertrophic cell layers (Fig. 2). Staining of the cartilage matrix with PAS and Alcian blue was normal but the intercolumnar septa were not calcified (Fig. 3). The metaphyseal side of the growth plate was very irregular; normal vascular invasion was lacking, while large buds of fibrous tissue penetrated from the mataphysis into the cartilage, giving an indented appearance at low magnification. Osteoid deposition was disorderly. Osteoclasts were numerous (Fig. 4). Large vacuoles were occasionally observed in swollen fibroblasts.

Primary metaphyseal trabeculae were lacking; the few secondary trabeculae had undergone intense remodelling and appeared surrounded by several layers of fibrous tissue (Fig. 5).

Beneath the periosteum the bone consisted of very thin lamellae; more than $3 / 4$ of the full thickness of the cortex was occupied by loose vascular connective tissue. Many osteoclasts were observed in each field but new bone was also being layed down by active osteoblasts (Fig. 6).

Autopsy confirmed multiple foci of bronchopneumonia with gray hepatization of the lungs. A few vacuolated macrophages were observed in the alveolar walls.

The liver was increased in volume and congested and many hepatocytes had vacuoles in the cytoplasm. Clear, cytoplasmic inclusions were also observed in the glomerular and epithelial cells of the proximal convoluted tubules of the kidney. Parathyroids glands were not found.

\section{Discussion}

The clinical and radiographic features of this case are those of mucolipidosis II $[2,5,7,8]$. The diagnosis was made on the basis of the decreased acid hydrolase activity in cultured fibroblasts and an increase of acid hydrolases in plasma. 


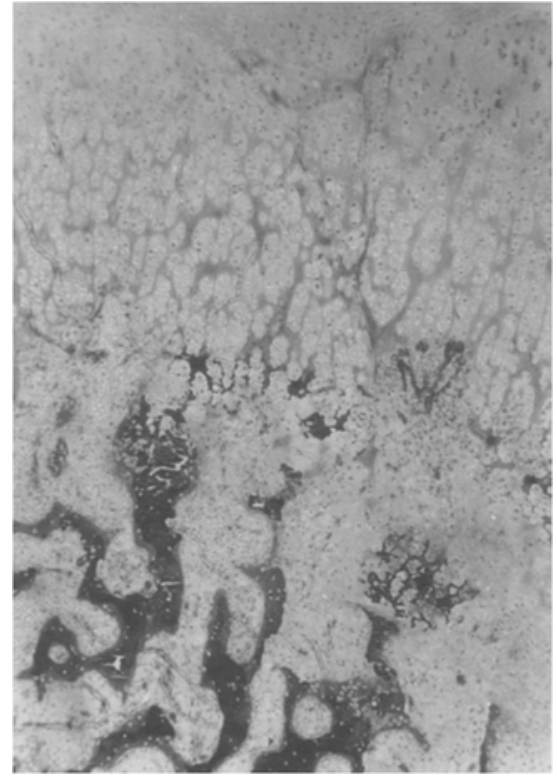

Fig. 3. Abnormally high columnar and hypertrophic cell layers of the growth plate cartilage and failure of intercolumnar septa calcification (von Kossa, $100 \times$ )
Few studies describe the pathology of bones in detail. Martin et al. [6] observed a marked disturbance of endochondral ossification with disarray of the proliferative and hypertrophic cell layers in an 8.5-months-old girl. Growth arrest of the epiphyseal plate and lack of the normal columnar arrangement was reported by Gilbert et al. [3] in three older children (aged 2, 6 and 8 years). In a 19-week fetus, Babcock et al. [1] observed decreased bone mineralization, a coarse trabecular pattern, shortened and under-modelled bones and sub-periosteal bone deficiency. The hypothesis common to all these studies is that the enzymatic defect in osteogenic cells may interfere directly with new bone deposition.

Ricket-like lesions and signs of hyperparathyroidism were present in our patient. Similar radiographic changes have been observed in other neonatal cases of mucolipidosis II [2, $5,7]$. Hypophosphataemic rickets was suspected at the age of 2 months on the basis of the high levels of serum alkaline phosphatase, hypophosphataemia and hyperphosphaturia. Whether hyperparathyroidism was secondary to hypophosphataemic rickets cannot be established from the data available.

Dysostosis developed later and was superimposed on the radiographic appearance of rickets. The pathogenesis of dys-
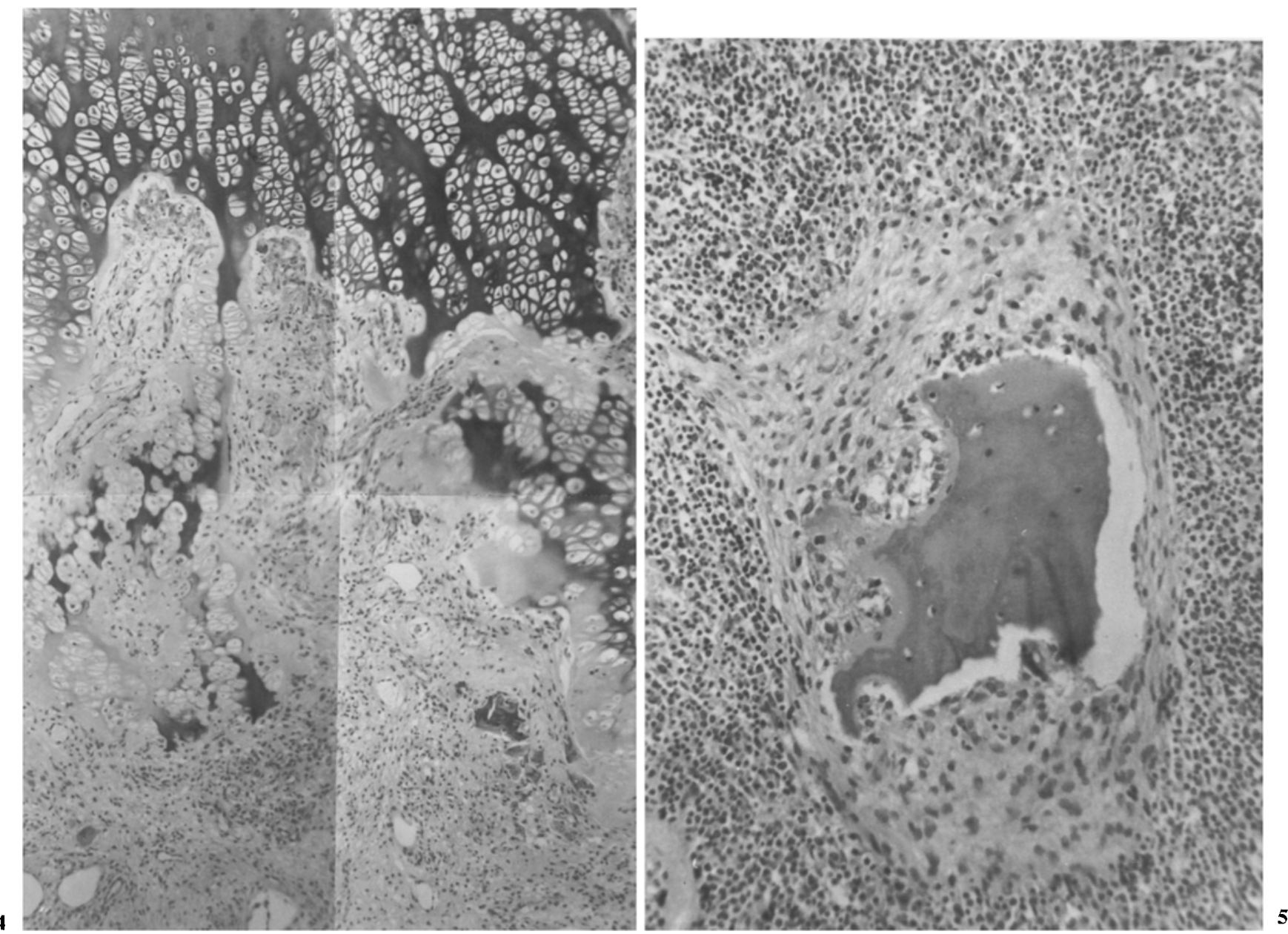

Fig. 4. The abnormal pattern of the growth-plate cartilage and metaphysis with rickets-like features (haematoxylin-eosin, $250 \times$ )

Fig. 5. Metaphyseal trabeculae are surrounded by several layers of fibrous tissue as is usually seen in hyperparathyroidism (haematoxylin-eosin, $250 \times)$ 


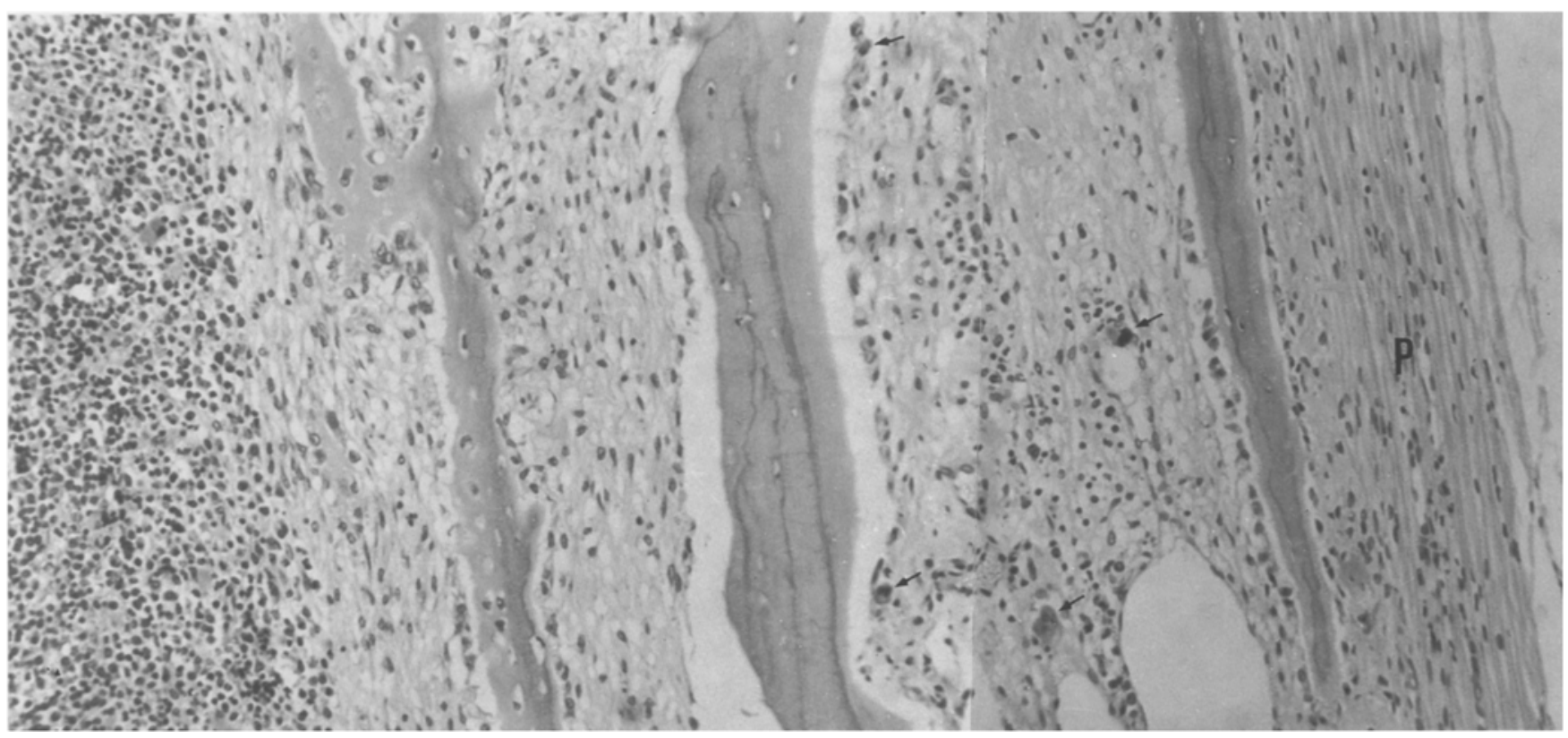

Fig. 6. Subperiosteal resorption is responsible for the cloaking-like aspects seen in X-rays. The full thickness of the cortex is undergoing fast remodelling ( $P$ = periosteum; arrows indicate osteoclasts) (haematoxylin-eosin, $100 \times$ )

ostosis multiplex is not clear but appears to be related to the defective lysosomal enzyme activity.

Mucolipidosis II is caused by defective processing of hydrolases which interferes with their entrance into lysosomes [4]. Based on experience with the other mucolipidoses and mucopolysaccharidoses this defect explains dysostosis multiplex but not the inhibition of calcification, ricket-like features and hyperparathyroidism observed in this infant with mucolipidosis II.

Cause of the defective mineralization and its relationship to the primary defect in neonatal mucolipidosis II remains obscure and deserves further study.

Acknowledgements. The authors wish to thank Prof. C. Danesino for the skin fibroblast culture and the acid hydrolase determination and Dr. V. Monafó who reviewed the English text.

\section{References}

1. Babcock DS, Bove KE, Hug G, Dignan PSJ, Soukup S, Warren WS (1986) Fetal mucolipidosis II (I-cell disease): radiologic and pathologic correlation. Pediatr Radiol 16:32-39

2. Baggio P (1978) I-cell disease. Mucolipidosi II o Sialidosi. Min Ped 30:865-884
3. Gilbert EF, Dawson G, Zu Rhein GM, Opitz JM, Spranger JW (1973) I-cell disease, mucolipidosis II. Histochemical Ultrastructural and biochemical observations in four cases. Z Kinderheilkd $114: 259-292$

4. Hickman S, Neufeld EF (1972) A hypothesis for I-cell disease: defective hydrolases that do not enter lysosomes. Biochem Biophys Res Commun 49:992-999

5. Lemaitre L, Remy T, Farriaux JP, Dhondt JL, Walbaum R (1978) Radiological signs of mucolipidosis II or I-cell disease. Pediatr Radiol 7:97-105

6. Martin JJ, Leroy JG, Farriaux JP, Fontaine G, Desnick RJ, Cabello A (1975) I-cell disease (mucolipidosis II). A report on its pathology. Acta Neuropathol (Berl) 33:285-305

7. Patriquin HB, Kaplan P, Kind HP, Giedion A (1977) Neonatal mucolipidosis II (I-cell disease): clinical and radiological features in three cases. Am J Roentgenol 129:37-43

8. Taber P, Gyepes MT, Phillippart M, Ling S (1975) Roentgenographic manifestation of Leroy's I-cell disease. Am J Roentgenol $118: 213-221$

9. Terashima Y, Tsuda K, Isomura S, Sugiura Y, Nogami H (1975) I-cell disease. Am J Dis Child 129:1083-1090

10. Tondeur M, Vamos-Hurwitz E, Mockel-Pohl J, Dereume JP, Cremer N, Loeb H (1971) Clinical, biochemical and ultrastructural studies in a case of chondrodystrophy presenting the I-cell phenotype in tissue culture. J Pediatr 79:366-378

Received January 21, 1988 / Accepted August 16, 1988 